\title{
Synthesis and anticancer effects of a-lipoic ester of alloxanthoxyletin
}

\author{
Wioletta Olejarz ${ }^{1,2} \cdot$ Małgorzata Wrzosek $\mathbb{1}^{1,2} \cdot$ Michał Jóźwiak $^{2,3} \cdot$ Emilia Grosicka-Maciąg $^{3} \cdot$ Piotr Roszkowski $^{4} \cdot$ \\ Agnieszka Filipek $^{5} \cdot$ Agnieszka Cychol $^{1,2} \cdot$ Grażyna Nowicka $^{1,2} \cdot$ Marta Struga $^{3}$
}

Received: 16 January 2019 / Accepted: 19 March 2019 / Published online: 1 April 2019

(c) The Author(s) 2019

\begin{abstract}
Upon analyzing the structure-activity relationship, it was found that coumarin-based derivatives exerted cytotoxic and antitumor activity. In the present study a new ester of $\alpha$-lipoic acid and derivative of alloxanthoxyletin (LAA) was synthesized and evaluated for its anticancer activity. The structure of this new compound was confirmed by ${ }^{1} \mathrm{H}$ NMR, ${ }^{13} \mathrm{C}$ NMR, and HRMS spectroscopic analyses. Both, the cytotoxicity and the migration tests showed that human melanoma cells (HTB-140) and human lung cancer cells (A549) were more sensitive to LAA exposure than human normal keratinocytes (HaCaT). Moreover, LAA induced significant HTB-140 and A549 apoptosis, as evidenced by V-FITC/7-AAD flow cytometry analysis. Preincubation of the HTB-140 and A549 cells with LAA increased a sensitivity of tumor cells to a druginduced cell death. Significantly lower expression of IL-6 mRNA was observed in A549 and HTB-140 cells which were preincubated with LAA and then treated with doxorubicin as compared to the cells pre-incubated with LAA and then treated with cisplatin. The results suggest that the newly synthetized LAA is compound with anticancer activity promising for potential applications, but further studies are needed to gain more insight into the mechanism of action of tested derivative.
\end{abstract}

Keywords Alloxanthoxyletin $\cdot \alpha$-lipoic acid $\cdot$ Antitumor activity

\section{Introduction}

Searching for new substances with anti-cancer properties is an important area of research. Several reports provided

Supplementary information The online version of this article (https:// doi.org/10.1007/s00044-019-02335-3) contains supplementary material, which is available to authorized users.

Małgorzata Wrzosek

malgorzata.wrzosek@wum.edu.pl

1 Faculty of Pharmacy, Department of Biochemistry and Pharmacogenomics, Medical University of Warsaw, 02-097 Warszawa, Poland

2 Laboratory of Biochemistry and Clinical Chemistry at the Centre for Preclinical Research, Medical University of Warsaw, Banacha 1B, 02-097 Warsaw, Poland

3 Chair and Department of Biochemistry, Medical University of Warsaw, 02-097 Warszawa, Poland

4 Faculty of Chemistry, University of Warsaw, Pasteura 1, 02-093 Warsaw, Poland

5 Faculty of Pharmacy, Department of Pharmacognosy and Molecular Basis of Phytotherapy, Medical University of Warsaw, 02-097 Warszawa, Poland evidence that natural and synthetic derivatives of coumarins exert cytotoxic and anticancer properties (Peng et al. 2013). Alloxanthoxyletin belongs to natural and biologically active pyranocoumarins which possess anticancer activity. Recent studies have indicated that coumarin derivatives reveal their cytotoxicity by several mechanisms with regard to their structure. It was shown that they are a potent inhibitor of variety of proteins including EGFR, tyrosine kinase, ERK1/ 2, PI3K, HSP 90, Bax, STAT, NF-кB, and telomerase (Kumar et al. 2017). Moreover, coumarin-based agents influence the caspase-9-mediated apoptosis by arresting the cell cycle in the G0/G1 phase, G2/M the and have DNA binding ability (Amin et al. 2018).

Alpha lipoic acid ( $\alpha$-LA) is a compound with antioxidant properties (Kaki et al. 2012). It is synthesized by plants and animals, can cross the blood-brain barrier, and is a cofactor of enzymes that play key role in cellular metabolism (Bernini et al. 2011). Alpha lipoic acid effectively scavenges free radical species and maintains a cellular oxidoreductive state (Packer et al. 1995). Recently, $\alpha$-lipoic acid has attracted an increasing interest due to its suggested effect in the therapy of many diseases, including different type of cancer. It is supposed that $\alpha$ - LA, as well as its derivatives may protect against tumorigenesis and cancer 
progression (Bernini et al. 2011, Wenzel et al. 2005). Bernini et al. observed the antiproliferative properties of $\alpha$ lipoic acid derivative against human colorectal adenocarcinoma HT-29 cells and showed that the inhibition of cancer cell growth, was mediated by the induction of a $\mathrm{G} 2 / \mathrm{M}$ phase cell cycle arrest (Bernini et al. 2011).

On the basis of recent studies concerning the biological and pharmacological properties of both coumarins and $\alpha$ lipoic acid, our research are focused on yielding a novel molecular combinations received by joining the two biologically active compounds to obtain a more active substance. Our previous study demonstrated that some alloxanthoxyletin derivatives revealed a high cytotoxic potential against human melanoma cells (HTB-140) and human epithelial lung carcinoma cells (A549) (Ostrowska et al. 2017), therefore, we decided to investigate a novel derivative of alloxanthoxyletin. In the present study new ester of $\alpha$-lipoic acid and derivative of alloxanthoxyletin (LAA) was synthesized and evaluated for its anticancer activity. The final ester (LAA) was obtained in the catalytic condensation. It seems reasonable that the synthesized LAA may comprise the biological activity of alloxanthoxyletin and its lipoic part may increase the affinity to penetrate cancer cells. Thus, it may be assumed that the tested derivative increases cancer drug sensitivity. To check this consideration we examined the effect of the tested derivative on HTB-140 and A549 cell lines with regard to their antiproliferative activities in vitro. Moreover, we aimed to perform cytotoxic evaluation of doxorubicin/cisplatin in combination with LAA in light of attenuated IL-6 gene expression.

\section{Materials and methods}

\section{General}

Dichloromethane, 1,4-dioxane, and methanol were supplied from Sigma Aldrich. All chemicals were of analytical grade and were used without any further purification. The NMR spectra were recorded on a Bruker AVANCE spectrometer operating at $500 \mathrm{MHz}$ for ${ }^{1} \mathrm{H} \mathrm{NMR}$ and at $125 \mathrm{MHz}$ for ${ }^{13} \mathrm{C}$ NMR. The spectra were measured in $\mathrm{CDCl}_{3}$ and are given as $\delta$ values (in ppm) relative to TMS. Mass spectral ESI measurements were carried out on Waters ZQ Micro-mass instruments with quadruple mass analyzer. LC analyses were performed on silica gel plates (Merck Kiesegel $\mathrm{GF}_{254}$ ) and visualized using UV light or iodine vapor. Column chromatography was carried out at atmospheric pressure using Silica Gel 60 (230-400 mesh, Merck) and using dichloromethane/methanol (0-1\%) mixture as eluent.

\section{Synthesis of a-LA ester of 7-hydroxy-5',5a',9- trimethylpyrano[2', $\left.3^{\prime}-\mathrm{f}\right]-(2 \mathrm{H})$-chromen-2-one}

To a magnetically stirred at $22-23{ }^{\circ} \mathrm{C}$ solution of 7 hydroxy-5',5a', 9-trimethylpyrano[2', $3^{\prime}$-f]-(2 H)-chromen-2one (derivative of alloxanthoxyletin) $(0.15 \mathrm{~g} ; 0.58 \mathrm{mmol})$ and $\alpha$-lipoic acid $(0.12 \mathrm{~g} ; 0.58 \mathrm{mmol})$ in dry 1,4 -dioxane: $\mathrm{CH}_{2} \mathrm{Cl}_{2}$ mixture $(2: 1,12 \mathrm{~mL})$ a $\mathrm{BOP}(0.26 \mathrm{~g} ; 0.58 \mathrm{mmol})$ and triethylamine $(0.12 \mathrm{~mL} ; 0.87 \mathrm{mmol})$ were added. The resulting solution was stirred at $22-23^{\circ} \mathrm{C}$ for $1 \mathrm{~h}$ and concentrated under reduced pressure. The residue was dissolved in $\mathrm{CH}_{2} \mathrm{Cl}_{2}(25 \mathrm{~mL})$ and washed with $1 \% \mathrm{HCl}_{\mathrm{aq}}$ solution $(4 \times 12 \mathrm{~mL})$ and distilled water $(2 \times 15 \mathrm{~mL})$. The organic layer was dried over $\mathrm{MgSO}_{4}$ and after evaporation of the solvent under reduced pressure the product was isolated using column chromatography on silica gel and $\mathrm{CH}_{2} \mathrm{Cl}_{2}: \mathrm{MeOH}$ mixture $(0-1 \% \mathrm{MeOH})$ as an eluent. The isolation by chromatography gave $0.16 \mathrm{~g}$ ( $62 \%$ yield) of ester of $\alpha$-lipoic acid and alloxanthoxyletin derivative (LAA) as pale yellow oil.

${ }^{1} \mathrm{H}$ NMR $\left(\mathrm{CDCl}_{3}, 300 \mathrm{MHz}\right) \delta(\mathrm{ppm}): 1.51$ (s, 5',5a'$6 \mathrm{H}), 1.53-1.64(\mathrm{~m}, 4$ "-2H, ), 1.70-1.78 (m, 5"-2H), 1.791.85 (m, 3"-2H), 1.90-1.97 (m, 7"-1H), 2.46-2.52 (m, 7"$1 \mathrm{H}), 2.59(\mathrm{~d}, J=1.5 \mathrm{~Hz}, 9-3 \mathrm{H}), 2.63(\mathrm{t}, J=7.5 \mathrm{~Hz}, 2$ "2H), 3.11-3.22 (m, 8"-2H), 3.58-3.63 (m, 6"-1H), $5.63(\mathrm{~d}$, $J=10.2 \mathrm{~Hz}, 3 '-1 \mathrm{H}), 6.06(\mathrm{q}, J=1.2 \mathrm{~Hz}, 3-1 \mathrm{H}), 6.30(\mathrm{~d}$, $\left.J=9.9 \mathrm{~Hz}, 4^{\prime}-1 \mathrm{H}\right), 6.64$ (s, 8-1 H). ${ }^{13} \mathrm{C}$ NMR $\left(\mathrm{CDCl}_{3}, 75\right.$ MHz) $\delta$ (ppm): 24.3 (C-9), 24.6 (C-3”), 27.9 (C-5', 5a'), 28.7 (C-4”), 33.9 (C-2"), 34.6 (C-5"), 38.5 (C-8”), 40.3 (C7”), 56.2 (C-6"), 78.1 (C-2'), 103.4 (C-8), 108.6 (C-4a), 110.8 (C-6), 114.0 (C-3), 115.9 (C-4'), 129.3 (C-3'), 148.4 (C-7), 152.3 (C-5), 153.5 (C-4), 154.4 (C-8a), 160.3 (C-2), 170.9 (C-1").

HRMS (ESI) calc. for $\mathrm{C}_{23} \mathrm{H}_{26} \mathrm{O}_{5} \mathrm{~S}_{2} \mathrm{Na} \quad[\mathrm{M}+\mathrm{Na}]^{+}$: 469.1119; found 469.1112 .

\section{Cell cultures}

Human immortal keratinocyte cell line from adult human skin ( $\mathrm{HaCaT}$ ), Human epithelial lung carcinoma cell line (A549), and Human melanoma cell line (HTB-140) were bought from American Type Culture Collection (Rockville, USA), and cultured in Dulbecco's Modified Eagle's Medium (DMEM) supplemented with $1 \%$ antibiotics (penicillin and streptomycin), and $10 \%$ heat-inactivated FBS-fetal bovine serum (Gibco Life Technologies, USA), at $37{ }^{\circ} \mathrm{C}$ and $5 \% \quad \mathrm{CO}_{2}$ atmosphere. Cells were passaged using trypsin-EDTA (Gibco Life Technologies, USA) and cultured in 24-well plates. Experiments were conducted in DMEM with $2 \%$ FBS. 


\section{Cell viability assessment by MTT assay}

The cell viability was assessed by determination of MTT salt [3-(4,5-dimethylthiazol-2-yl)-2,5-diphenyltetrazolium bromide] conversion by mitochondrial dehydrogenase. Briefly, the cells were incubated for $72 \mathrm{~h}$ in 24-well plates with different concentrations of tested compounds, and subsequently for another $4 \mathrm{~h}$ with $0.5 \mathrm{mg} / \mathrm{ml}$ of MTT solution, which is converted in live cells under the effect of mitochondrial dehydrogenase into insoluble formazan. The converted dye was then solubilized in $0.04 \mathrm{M} \mathrm{HCl}$ in absolute isopropanol. Absorbance of solubilized formazan was measured spectrophotometrically at $570 \mathrm{~nm}$ (using Epoch microplate reader, BioTek Inc., USA) equipped with Gen5 software (BioTech Instruments,Inc., Biokom). Cell viability was presented as a percent of MTT reduction in the treated cells versus the control cells (cells incubated in serum-free DMEM without studied compounds). The relative MTT level (\%) was calculated as $[\mathrm{A}] /[\mathrm{B}] \times 100$, where $[\mathrm{A}]$ is the absorbance of the test sample and $[\mathrm{B}]$ is the absorbance of control sample containing the untreated cells. Decreased relative MTT level indicates decreased cell viability.

\section{LDH assay}

Release of lactate dehydrogenase (LDH) from the cytosol to culture medium (cellular membrane integrity assessment) is a marker of cell death. The assay was performed after $72 \mathrm{~h}$ incubation of cells in 24-well plates with investigated compounds according to previously used methodology. The activity of lactate dehydrogenase (LDH) released from cytosol of damaged cells to the supernatant was measured according to the protocol of LDH test described by the manufacturer (Roche Diagnostics, Germany). An absorbance was measured at $490 \mathrm{~nm}$ using a microplate reader (using Epoch microplate reader, BioTek Inc., USA) equipped with Gen5 software (BioTech Instruments, Inc., Biokom). Compound mediated cytotoxicity expressed as the LDH release (\%) was determined by the following equation: [(A test sample-A low control)/(A high control -A low control)] $\times 100 \%$ (A-absorbance); where "low control" were cells in DMEM with 2\% FBS without tested compounds and "high control" were cells incubated in DMEM with $2 \%$ FBS with $1 \%$ Triton X-100 (100\% LDH release). The cytotoxicity was expressed as percentage $\mathrm{LDH}$ release as compared to the maximum release of $\mathrm{LDH}$ from Triton-X100-treated cells.

\section{Cell migration assay}

Cells were seeded in 12-well plates, next after reaching a $70 \%$ confluence, and a cutting line in the middle of the plate was made and the test compound was added at two concentrations of $20 \mu \mathrm{M}$ and $40 \mu \mathrm{M}$ (these concentrations were not cytotoxic to the cells). Cells were incubated for $72 \mathrm{~h}$, and then the pictures were obtained through a microscope Nikon Eclipse TS 100. The total number of cells and the number of cells that crossed the cutting line were counted, and the percent of inhibition of cell migration as compared to control cells was calculated.

\section{Annexin V binding assay}

Cells were pre-incubated for $72 \mathrm{~h}$ with the tested compound LAA at $\mathrm{IC}_{50}$ concentration. The effect of compound exposure on HaCaT, A549, and HTB-140 cells was determined by dual staining with Annexin V:FITC and 7$\mathrm{AAD}$, using the commercially available kit (FITC Annexin V Apoptosis Detection Kit I; BD Biosciences Pharmingen). Annexin V:FITC and 7-AAD were added to the cellular suspension as in the manufacturer's instructions, and sample fluorescence of 10,000 cells was analyzed by flow cytometry (Becton Dickinson). Cells which were Annexin $\mathrm{V}$ :FITC positive and 7-AAD negative were identified as early apoptotic. Cells which were Annexin V:FITC positive and 7-AAD positive were identified as cells in late apoptosis or necrotic.

\section{Quantitative real-time RT-PCR for IL-6 mRNA analysis}

RNA was extracted using TRIzol $^{\bullet}$ Reagent (Ambion) according to the manufacturer's instruction. RNA concentration and purity were evaluated with Quawell Q5000 micro-volume UV-Vis spectrophotometer. RNA was reverse transcribed to cDNA with High-Capacity RNA-tocDNA Kit (Applied Biosystems).

Quantitative real-time reverse transcription polymerase chain reaction (qRT-PCR) was carried out with TaqMan Gene Expression Assays (Applied Biosystems) by using the $V_{\text {ViiA }}{ }^{\mathrm{TM}} 7$ Real-Time PCR System (Applied Biosystems). VIC-labeled TaqMan probe for IL-6 (Hs00174131_m1), and FAM-labeled TaqMan probe for GAPDH (Hs03929097_g1) were used. All qRT-PCR experiments were run in triplicate. The PCR reaction mix included TaqMan Gene Expression Assay, TaqMan Universal PCR Master Mix II, with Uracil-N-Glycosylase (UNG, Applied Biosystems) added to each cDNA sample or blank control. The PCR cycling conditions were $50^{\circ} \mathrm{C}$ for $2 \mathrm{~min}$ for UNG activity, $95{ }^{\circ} \mathrm{C}$ for $10 \mathrm{~min}$ to activate the polymerase, followed by 40 cycles of annealing and extension step at $95{ }^{\circ} \mathrm{C}$ for $15 \mathrm{~s}$ and $60^{\circ} \mathrm{C}$ for $60 \mathrm{~s}$. Expression levels of IL-6 were normalized to GAPDH level and relative quantification of the IL- 6 gene was performed using the $2^{-\Delta \Delta \mathrm{Ct}}$ method. 
Scheme 1 Synthesis of ester of $\alpha$-lipoic acid and derivative of alloxanthoxyletin (LAA)

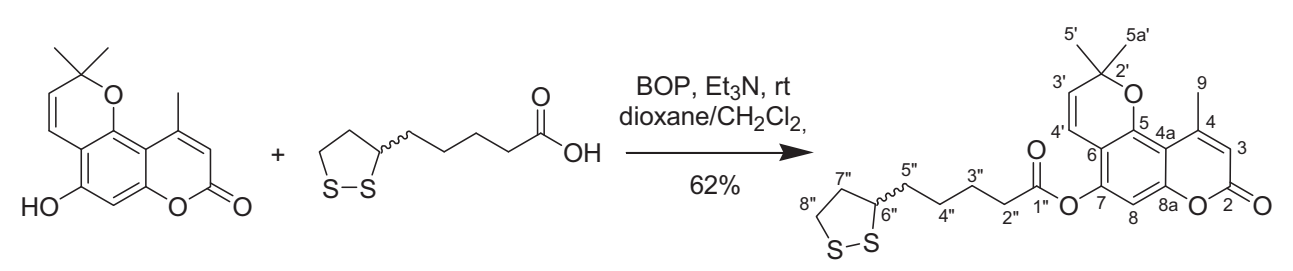

\section{Statistical analysis}

All presented experiments were repeated at least three times. The results are expressed as the mean \pm SD from the indicated number of experiments. Comparisons were made using Student's $t$-test and one way analysis of variance. Differences between experimental groups were considered to be statistically significant at $p<0.05$.

\section{Results and discussion}

\section{Synthesis of ester of $a$-lipoic acid and derivative of alloxanthoxyletin}

Derivative of alloxanthoxyletin was obtained using two different methods. The first approach started with the reaction of 5,7-dihydroxy-4-methylcoumarin with 4,4dimethoxy-2-methylbutan-2-ol. Application of the two-step crystallization yielded two products: 7-hydroxy-5,5a',9-trimethylpyrano[2', $\left.3^{\prime}-\mathrm{f}\right]-(2 \mathrm{H})$-chromen-2-one (derivative of alloxanthoxyletin) (from benzene) and 7-hydroxy-5',5a',9trimethylpyrano[2', $3^{\prime}$-f]-(8 H)-chromen-2-one (from methanol), however such method of synthesis was relatively time-consuming.

In the second approach we have used the same substrates but under microwave conditions. Despite the need to use column chromatography such approach allowed us to obtain the products much faster. Synthesis and characteristic of the alloxanthoxyletin derivative was described before (Ostrowska et al. 2017). Alpha lipoic acid ( $\pm 1,2-$ Dithiolane3-pentanoic acid) was used as a second substrate for synthesis and it was supplied from Sigma Aldrich. The synthesis was carried out under room conditions in 1,4dioxane and BOP ((Benzotriazol-1-yloxy)tris(dimethylamino)phosphonium hexafluorophosphate) was used as a catalyst.

Synthesis of $\alpha$-lipoic acid ester of 7-hydroxy-5',5a',9trimethylpyrano[2', $\left.3^{\prime}-\mathrm{f}\right]-(2 \mathrm{H})$-chromen-2-one (LAA) is shown in Scheme 1.

\section{Biological studies}

The purpose of this study was to evaluate cytotoxic activity of the synthetized ester of $\alpha$-lipoic acid and derivative of
Table 1 Cytotoxic activity of tested compounds

\begin{tabular}{|c|c|c|c|c|c|}
\hline & \multicolumn{4}{|l|}{ Cancer cells } & \multirow{3}{*}{$\begin{array}{l}\text { Normal cells } \\
\mathrm{HaCaT} \\
\mathrm{IC}_{50}\end{array}$} \\
\hline & \multicolumn{2}{|l|}{ HTB-140 } & \multicolumn{2}{|l|}{ A549 } & \\
\hline & $\mathrm{IC}_{50}$ & SI & $\mathrm{IC}_{50}$ & SI & \\
\hline LAA & $34.10 \pm 7.91$ & 1.6 & $37.20 \pm 5.62$ & 1.5 & $55.50 \pm 4.51$ \\
\hline cisplatin & $1.13 \pm 0.19$ & 2.5 & $1.95 \pm 0.83$ & 1.5 & $2.84 \pm 1.06$ \\
\hline doxorubicin & $0.47 \pm 0.18$ & 2.3 & $0.63 \pm 0.21$ & 1.7 & $1.09 \pm 0.23$ \\
\hline
\end{tabular}

Data are given as $\mathrm{IC}_{50}[\mu \mathrm{M}]$ and $\mathrm{SI}$

The $\mathrm{IC}_{50}$ is defined as the concentration of the compound that corresponds to a $50 \%$ growth inhibition. Data are expressed as mean \pm SD. The SI (Selectivity Index) was calculated for each compounds using formula: $\mathrm{SI}=\mathrm{IC}_{50}$ for normal cell line $/ \mathrm{IC}_{50}$ cancer cell line

$\mathrm{HaCaT}$ human immortal keratinocyte cell line from adult human skin, A549 human epithelial lung carcinoma cell line, HTB-140 human melanoma cell line

alloxanthoxyletin (LAA). Applied tests were conducted on normal cells: human immortal keratinocyte cell line from adult human skin (HaCaT) and two tumor cell lines: human melanoma cell line (HTB-140) and human epithelial lung carcinoma cell line (A549). As reference compounds two commonly used anti-cancer drugs: cisplatin and doxorubicin were used. The cytotoxic activity of the tested derivative LAA was specified by determining the $\mathrm{IC}_{50}$ (inhibitory concentrations), i.e., the concentrations of a test compound, which inhibited cells' viability and growth by $50 \%$ as compared to the controls. $\mathrm{IC}_{50}$ presented in Table 1 indicates that tested compound LAA was less toxic to HaCaT (normal) human cells than to cancer cell lines. Studied LAA showed cytotoxic potential against HTB-140 and A549 cells with $\mathrm{IC}_{50}$ of 34.10 and $37.20 \mu \mathrm{M}$, respectively (Table 1). Moreover, 7-hydroxy-5',5a',9-trimethylpyrano[2',3'-f]-(2 H)-chromen-2-one) served as a starting compound in the synthesis of LAA exhibited lower cytotoxicity than LAA against both tumor cell lines, with $\mathrm{IC}_{50}$ values 43.97 toward the HTB-140 cell lines, and with $\mathrm{IC}_{50}$ values 57.82 toward the A549 cell lines (For rev. see: Ostrowska et al. 2017).

To express a cytotoxic capacity of the LAA against cancer cells a selectivity factor (Selectivity Index, SI) was determined (Badisa et al. 2014). SI values higher than 1.0 indicates, that the substance expresses a higher toxicity against the cancer cells than against the normal cells. It was recognized that the selectivity index (SI) for the ester of 
Fig. $1 \mathrm{LDH}$ release as a marker of cell death in the $\mathrm{HaCaT}$, A549 and HTB-140 cells, treated for $72 \mathrm{~h}$ with different concentrations of the LAA. Data are expressed as the mean \pm SD from three independent experiments performed in triplicate

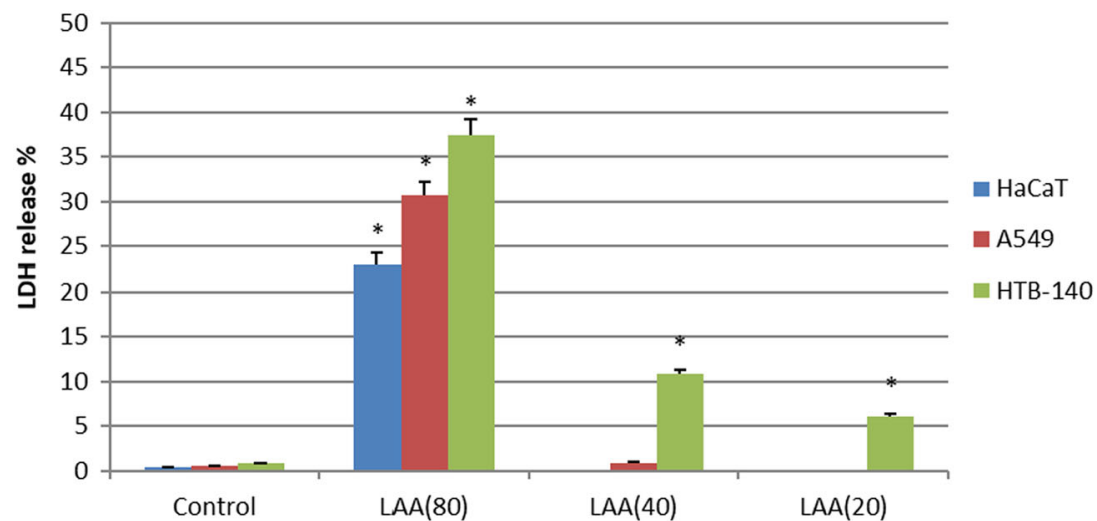

$\alpha$-lipoic acid and derivative of alloxanthoxyletin (LAA) was similar to that observed for the reference chemotherapeutics in the A549 cells (Table 1).

Assessment of the LDH release as a marker of cell death showed that $\alpha$-lipoic acid ester of alloxanthoxyletin (LAA) at the concentration of $80 \mu \mathrm{M}$ expressed strong cytotoxicity against studied cell lines and in the case of tumor cells the effect was greater (Fig. 1).

Moreover, tested LAA significantly $(p<0.001)$ inhibited cell migration and this effect was stronger on HTB-140 and A549 cells than on HaCaT cells (Fig. 2). LAA at a concentration of $20 \mu \mathrm{M}$ inhibited the A549 cell migration by $39.5 \%$, HTB-140 cell migration by $47.9 \%$ and HaCaT cell migration by $35.7 \%$. When compound was used at a concentration of $40 \mu \mathrm{M}$, the A549 cell migration was inhibited by $49.2 \%$, HTB-140 cell migration by $56.4 \%$, HaCaT cell migration by $47.9 \%$ (Fig. 2).

In order to check whether the synthetized $\alpha$-lipoic acid ester of alloxanthoxyletin (LAA) induces apoptosis in cells, we performed annexin V-FITC/7-AAD flow cytometry analysis. This assay identifies early apoptotic cells, and late apoptotic and necrotic cells. Cells that are stained positive for annexin $\mathrm{V}$ and negative for 7-AAD (shown at the lower right quadrant in Figs. 3-5) are early apoptotic. The incubation of HTB-140 and A549 cells for $72 \mathrm{~h}$ with LAA resulted in more than 1,5-times higher percentage of early and late apoptotic cells as compared to HaCaT cells. The tested alloxanthoxyletin derivative (LAA) induced early apoptosis in about 30\% of cancer HTB-140 and A549 cells and in about $18 \%$ of normal HaCaT cells (Figs. 3-5).

In vitro drug sensitivity testing in HaCaT, HTB-140, and A549 cells were also performed. Cells were pre-incubated with LAA for 24 or $48 \mathrm{~h}$ and then incubated with a chemotherapeutic agent (cisplatin or doxorubicin). The effect of the tested LAA on drug-induced cell death was higher in tumor cells (HTB-140, A549) than in normal cells (HaCaT) (Fig. 6). In order to confirm the obtained effect, we decided to check the influence of $\alpha$-lipoic acid on the examined cells in combination with cytostatics (cisplatin or doxorubicin).
Preincubation of the cells with LAA increased a sensitivity of tumor cells to a drug-induced cell death (Fig. 6) more effectively than preincubation of the cells with $\alpha$-lipoic acid. In cancer cells the strongest effect was observed in HTB140 cells. Pre-incubation of these cells with LAA for $24 \mathrm{~h}$ and then with cisplatin for $48 \mathrm{~h}$ resulted in a reduction of cell viability to $54.7 \pm 3.1 \%$ (Fig. 6). When doxorubicin was added, after addition of LAA for $24 \mathrm{~h}$, cell viability was reduced to $44.4 \pm 6.5 \%$. Thus, incubation with LAA ( $24 \mathrm{~h})$ and then with doxorubicin $(48 \mathrm{~h})$ seems to be the most effective protocol.

When A549 cells were pre-incubated for $24 \mathrm{~h}$ with our derivative LAA their viability was also significantly decreased to $55.4 \pm 2.6 \%$ in experiments with cisplatin, and to $47.2 \pm 5.4 \%$ in experiments with doxorubicin.

We hypothesize that reducing the time of exposure to cisplatin or doxorubicin by formulating protocol of incubation with LAA (24 h) and then with chemotherapeutic agent $(48 \mathrm{~h})$ can reduce the side effect of chemotherapy on $\mathrm{HaCaT}$ cells while preserving its cytotoxicity against HTB140 and A549 cells. However, chemotherapeutic agents can not only induce tumor cell apoptosis but also trigger inflammation in the tumor microenvironment. Proinflammatory factors, such as IL-6 are involved in multi drug resistance. It has been shown that increased IL-6 gene expression correlates with poor prognosis and chemoresistance (Wang et al. 2010; Gao et al. 2016). Thus, in the present study, the effect of addition of LAA, before incubation with commonly used anticancer drugs (cisplatin and doxorubicin), on the IL-6 mRNA expression was investigated (Fig. 7). Reduced IL-6 mRNA expression in experiments with doxorubicin compared to cisplatin was observed in A549 and in HTB-140 cells (Fig. 7). Significantly lower expression of IL-6 mRNA was observed in A549 cells which were pre-incubated for $24 \mathrm{~h}$ with LAA and then treated with doxorubicin for $48 \mathrm{~h}$ as compared to the cells pre-incubated with LAA for $24 \mathrm{~h}$ and then treated with cisplatin for $48 \mathrm{~h}$. Furthermore, in this therapy the cell viability was also significantly reduced, Fig. 6. As shown in 
Fig. 2 Microscopic examination of cell migration $\mathbf{a}$. HaCaT, $\mathbf{b}$. HTB-140, c. A549 cells
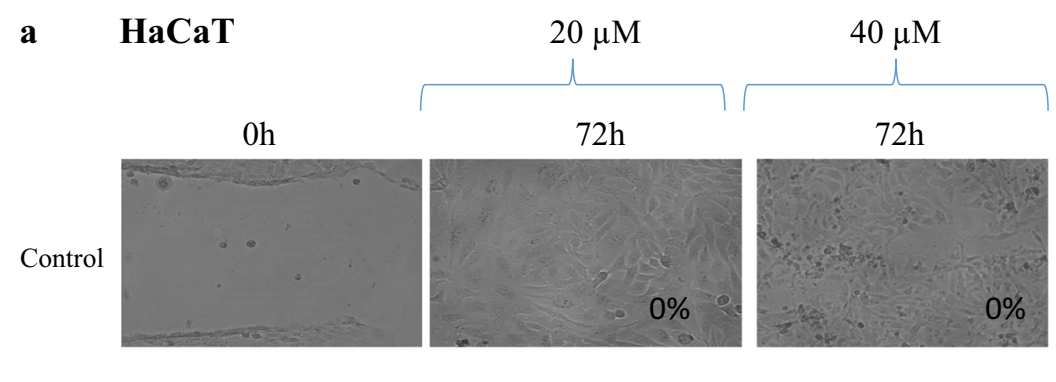

LAA
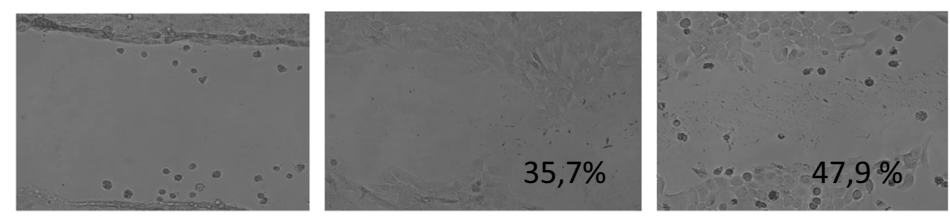

b

A549

LAA
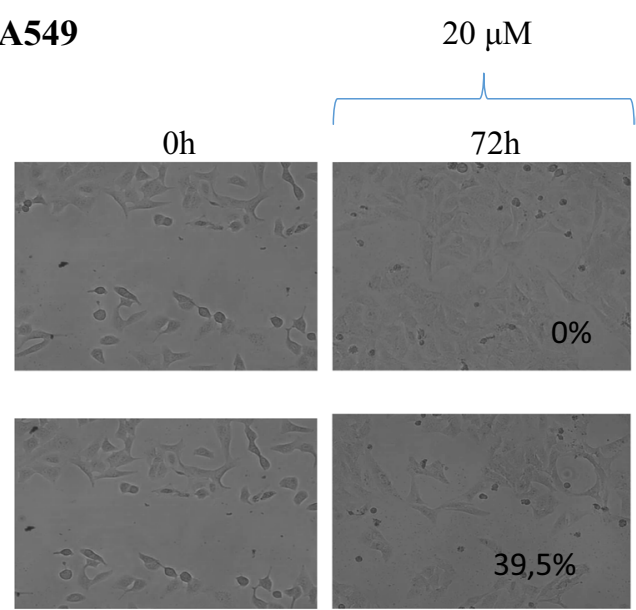

$40 \mu \mathrm{M}$
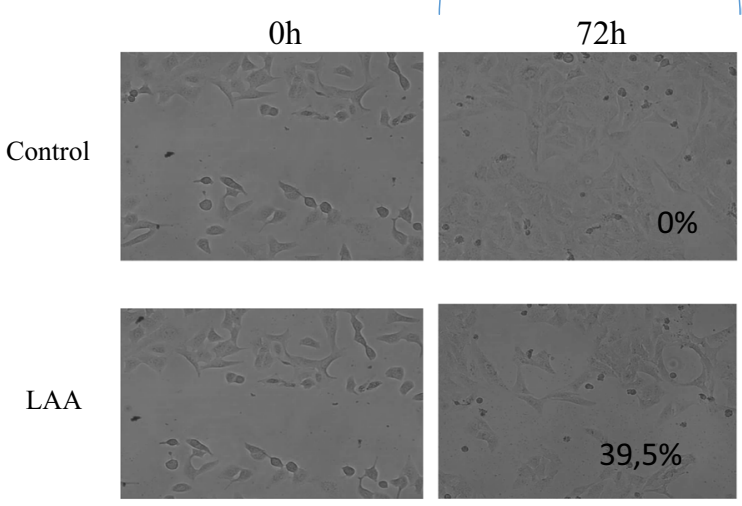

c

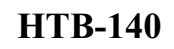

Oh
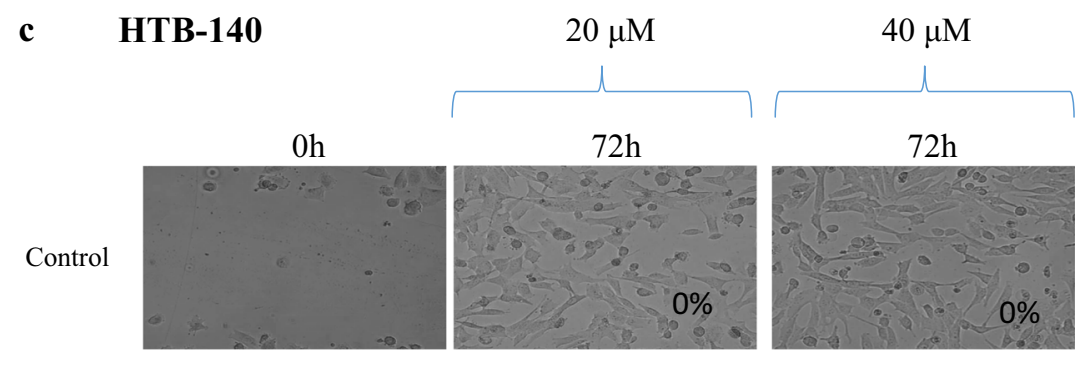

LAA
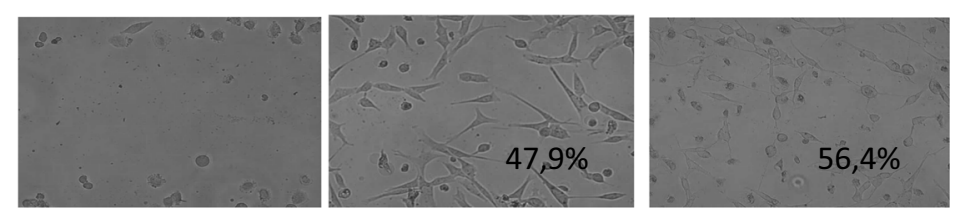

Fig. 7 the proposed therapy in HTB-140 cells was associated with a significantly lower IL-6 mRNA expression levels when compared with A549 cells. The greatest effects on lowering expression of IL-6 in HTB-140 cells has preincubation for $24 \mathrm{~h}$ with the tested compound LAA and then treatment with doxorubicin for $48 \mathrm{~h}$. Therefore, this therapy may be a promising strategy of treatment human melanoma and modulation of IL-6 expression, as well as its related signaling pathways.

\section{Conclusion}

Both, the cytotoxicity and the migration tests showed that human melanoma cells (HTB-140) and human lung cancer cells (A549) were sensitive to newly synthetized ester of $\alpha$ lipoic acid and alloxanthoxyletin. The tested compound induced apoptosis in the cancer cells and increased a sensitivity of tumor cells to a drug-induced cell death in experiments with cisplatin and doxorubicin, where exposure 
Fig. 3 The effect of the synthetized $\alpha$-lipoic acid ester of alloxanthoxyletin (LAA) on either early or late apoptosis in $\mathrm{HaCaT}$ as detected by flow cytometry. Cells were incubated for $72 \mathrm{~h}$ with $\mathrm{IC}_{50}$ concentration of the studied compound, the cells were harvested, stained with Annexin V-FITC and 7AAD, and analyzed by flow cytometry. Data are expressed as $\%$ of Annexin V-FITC-negative and 7-AAD-negative cells (early state of apoptosis) and as $\%$ of Anexin V-FITC and 7-AADpositive cells (late stage of apoptosis or necrosis). Diagrams of FITC-Annexin V/7-AAD flow cytometry in a representative experiment are presented. The lower right quadrants represent the cells in the early stage of apoptosis. The upper right quadrants contain the cells in the late stage of apoptosis or necrosis. ${ }^{*} p<0.001$ as compared with controls

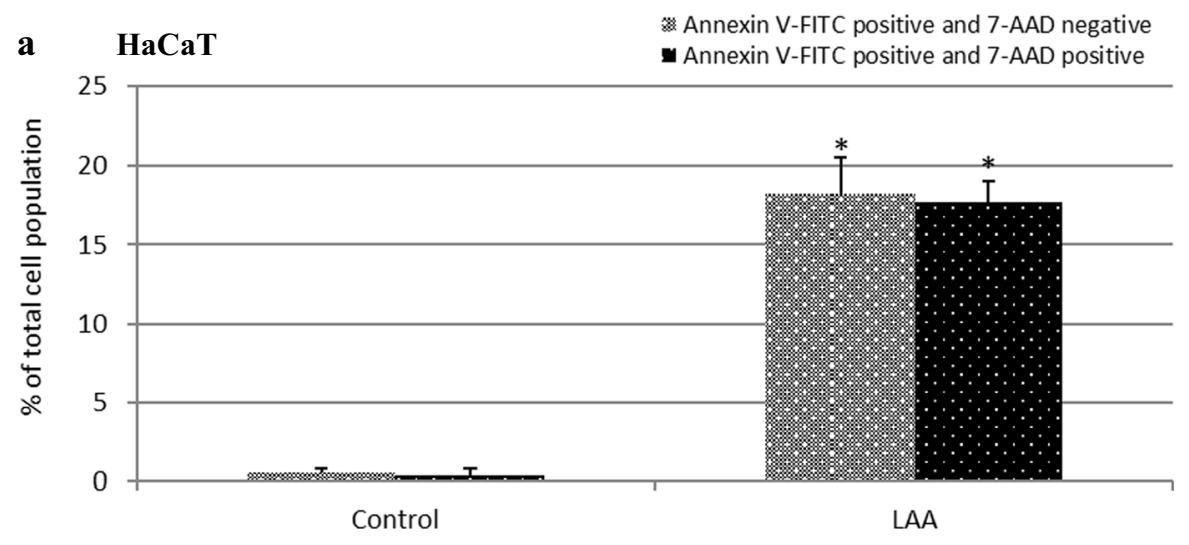

b
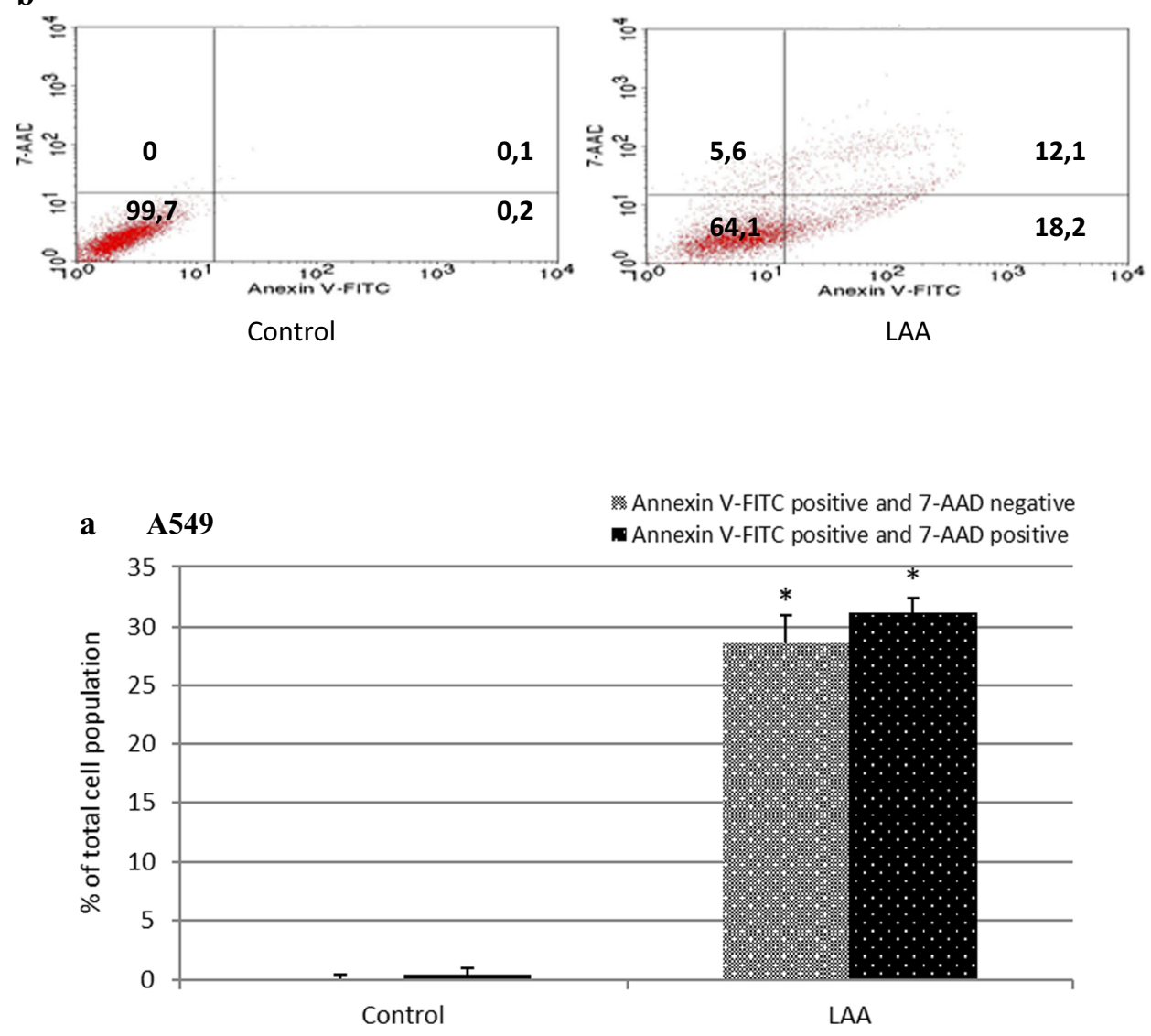

b
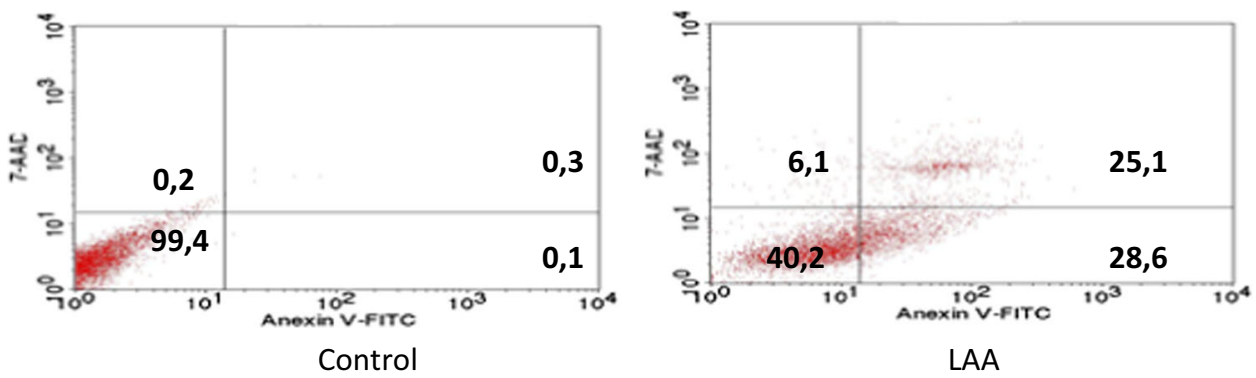
Fig. 5 The effect of the synthetized $\alpha$-lipoic acid ester of alloxanthoxyletin (LAA) on either early or late apoptosis in HTB-140 as detected by flow cytometry. Cells were incubated for $72 \mathrm{~h}$ with $\mathrm{IC}_{50}$ concentration of the studied compound, the cells were harvested, stained with Annexin V-FITC and 7$\mathrm{AAD}$, and analyzed by flow cytometry. Data are expressed as $\%$ of Annexin V-FITC- and 7AAD-negative cells (early state of apoptosis) and as \% of Anexin V-FITC and 7-AADpositive cells (late stage of apoptosis or necrosis). Diagrams of FITC-Annexin V/7-AAD flow cytometry in a representative experiment are presented. The lower right quadrants represent the cells in the early stage of apoptosis. The upper right quadrants contain the cells in the late stage of apoptosis or necrosis. $* p<0.001$ as compared with controls

a HTB-140

Annexin V-FITC positive and 7-AAD negative

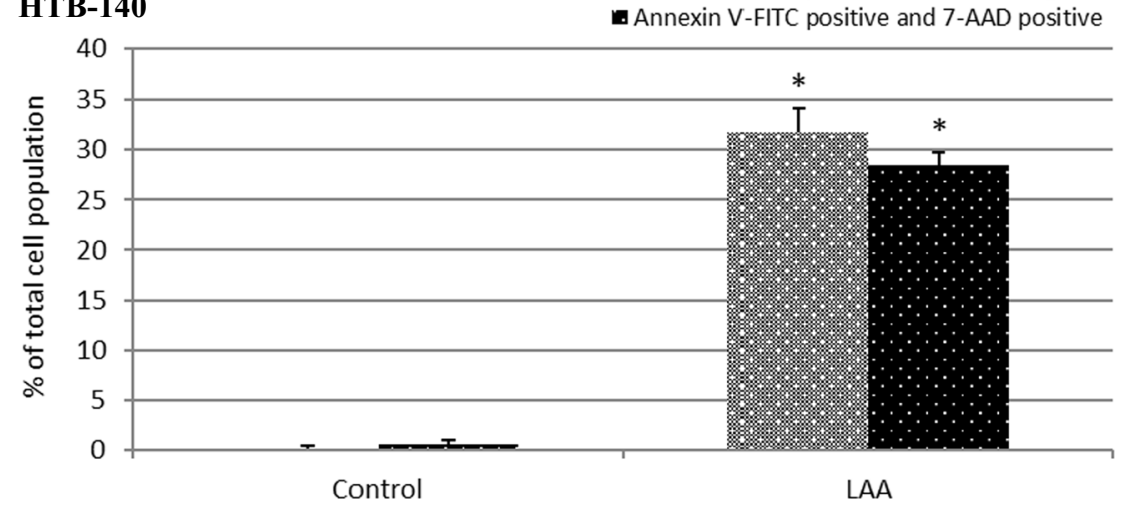

b

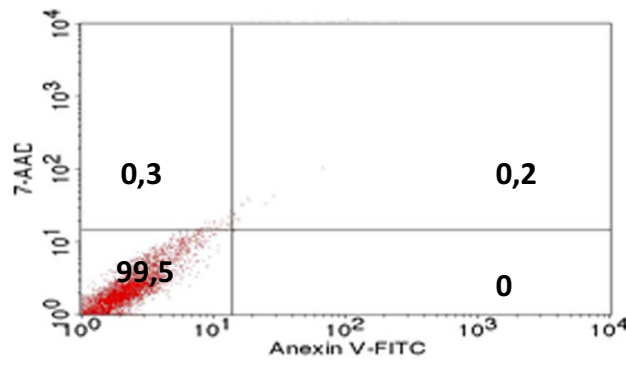

Control

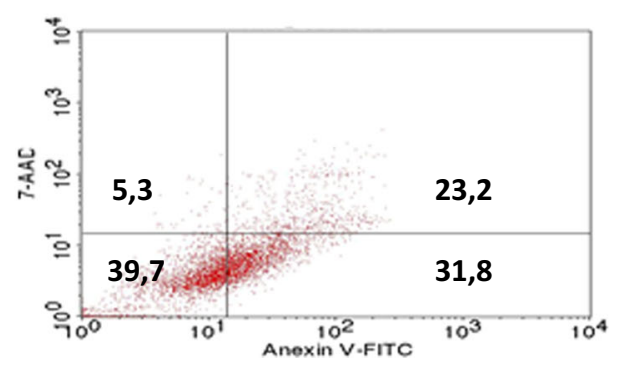

LAA

Fig. 6 In vitro drug sensitivity of HaCaT, A549 and HTB-140 cells. Cell viability assessed by MTT mitochondrial conversion in cells treated for 24 and $48 \mathrm{~h}$ with $\mathrm{IC}_{50}$ concentration of tested compounds and next by 48 or $24 \mathrm{~h}$ with a. Cisplatin, b. Doxorubicin. The relative MTT level $(\%)$ was calculated as $[\mathrm{A}] /$ $[\mathrm{B}] \times 100$, where $[\mathrm{A}]$ is the absorbance of the test sample and $[\mathrm{B}]$ is the absorbance of control sample containing the untreated cells. Decreased relative MTT level indicates decreased cell viability. Data are expressed as means $\pm \mathrm{SD}$. $* * p<$ $0.01, * p<0.001$ as compared to cisplatin or doxorubicin

a
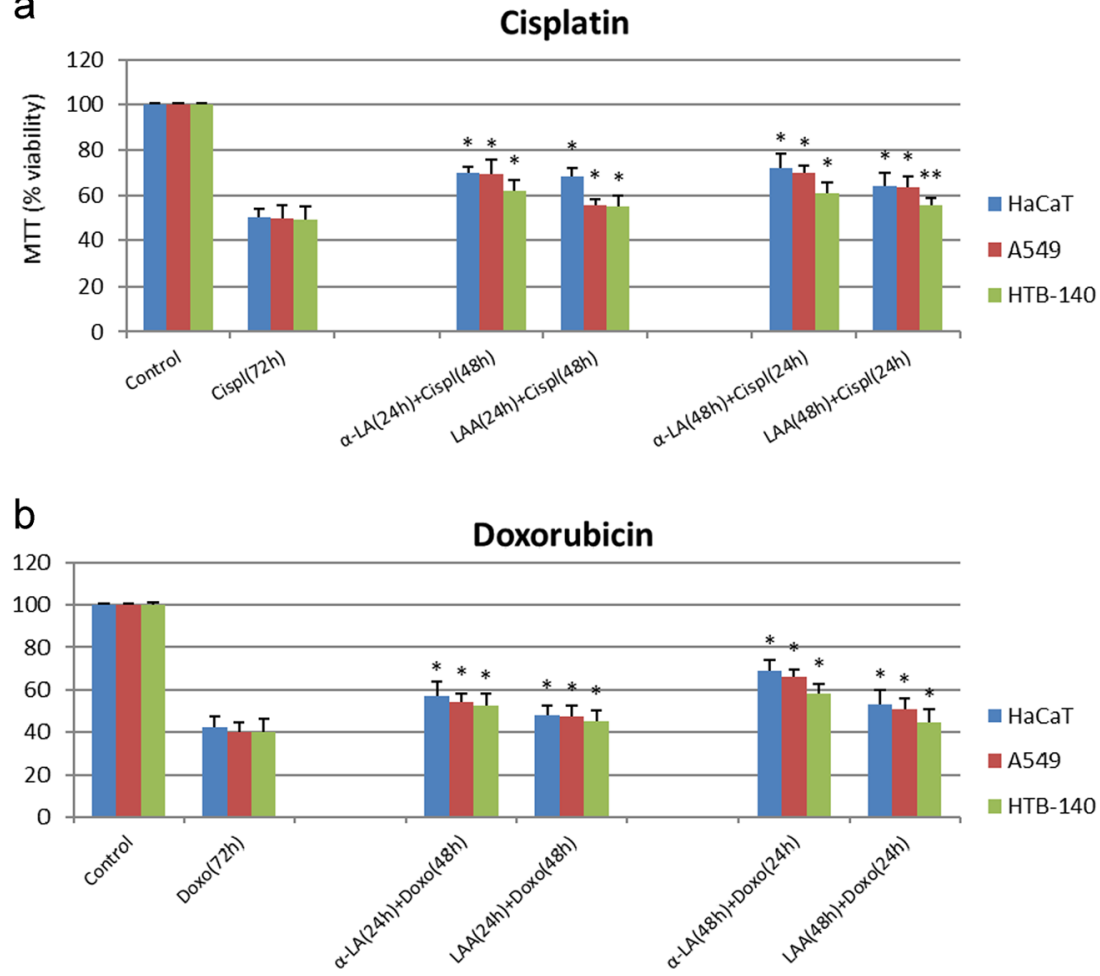

time to chemotherapy was reduced from $72 \mathrm{~h}$ to $48 \mathrm{~h}$. Moreover, incubation of the A549 and HTB-140 cells with LAA, prior to addition of doxorubicin, was associated with higher reduction of IL-6 mRNA expression than incubation of the cells with LAA, prior to addition of cisplatin. The results suggest that the compound is promising for potential 
Fig. 7 IL-6 mRNA expression in HaCaT, A549 and HTB-140 cells treated for 24 and $48 \mathrm{~h}$ with $\mathrm{IC}_{50}$ concentration of tested compound (LAA) and next by 48 or $24 \mathrm{~h}$ with cisplatin or doxorubicin. All data were normalized to untreated controls. IL-6 expression levels were quantified using qRT-PCR. Gene expression was normalized to the housekeeping gene GAPDH $(* * p<0.01 ; * p<$ $0.001)$. The A549 cell lines had increased IL-6 mRNA levels compare to HTB-140 cell lines

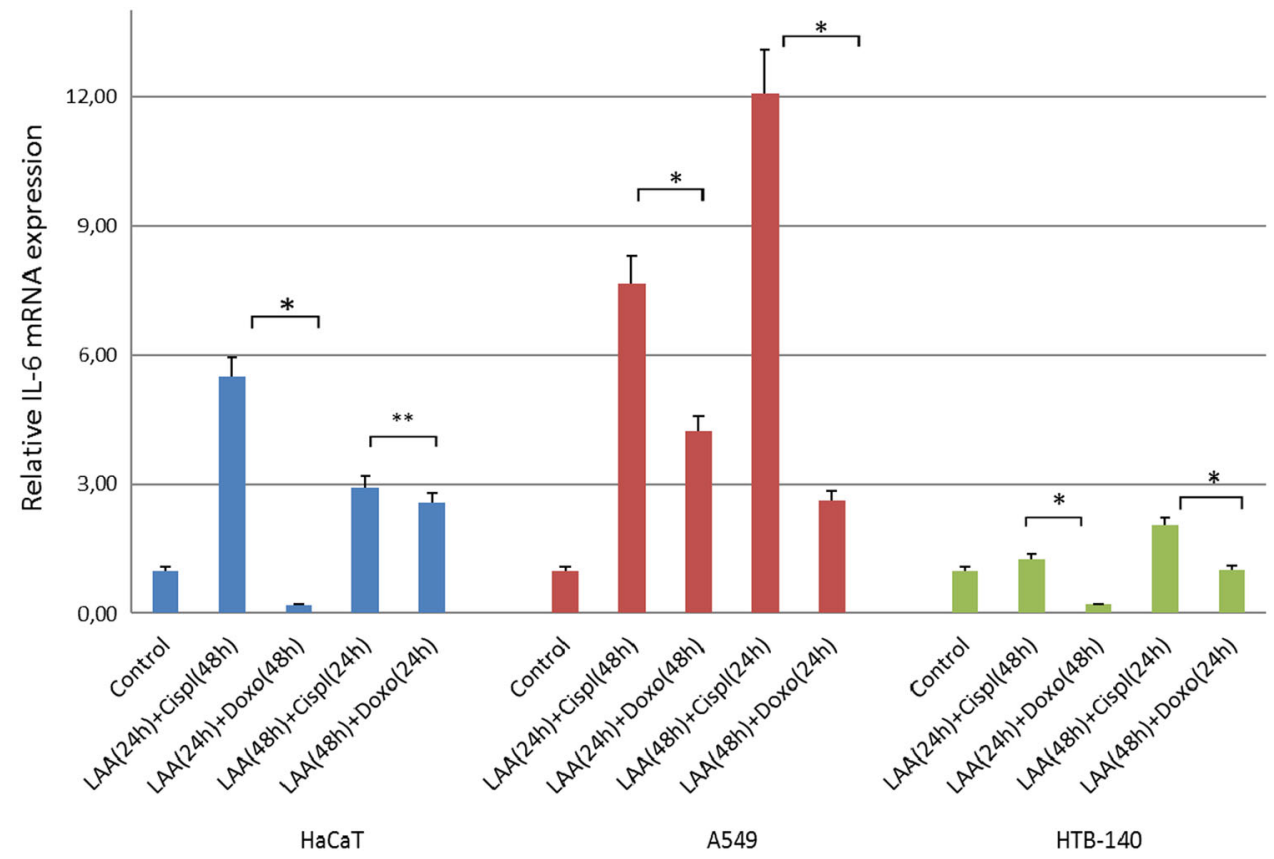

future applications, but further studies are needed to confirm these results and gain more insight into the mechanism of action of tested derivative.

Acknowledgements This work was supported by the Medical University of Warsaw and carried out with the use of CePT infrastructure financed by the European Union-the European Regional Development Fund within the Operational Programme Innovative Economy for 2007-2013. This work was supported by the Polish National Science Centre under the grant PRELUDIUN number UMO-2017/25/N/NZ7/ 01583 and the statutory founds of Department of Biochemistry and Pharmacogenomics and Chair and Department of Biochemistry, Medical University of Warsaw. We would like to thank Mr Marek Głowala from the Medical University of Warsaw for the technical assistance.

\section{Compliance with ethical standards}

Conflict of interest The authors declare that they have no conflict of interest.

Publisher's note: Springer Nature remains neutral with regard to jurisdictional claims in published maps and institutional affiliations.

Open Access This article is distributed under the terms of the Creative Commons Attribution 4.0 International License (http://crea tivecommons.org/licenses/by/4.0/), which permits use, duplication, adaptation, distribution, and reproduction in any medium or format, as long as you give appropriate credit to the original author(s) and the source, provide a link to the Creative Commons license, and indicate if changes were made.

\section{References}

Amin KM, Taha AM, George RF, Mohamed NM, Elsenduny FF (2018) Synthesis, antitumor activity evaluation, and DNA- binding study of coumarin-based agents Arch Pharm. 351:1700199. https://doi.org/10.1002/ardp.201700199

Badisa RB, Mina DA, Latinwo LM, Soliman KF (2014) Selective anticancer activity of neurotoxin 1-methyl-4-phenylpyridinium on non-small cell lung adenocarcinoma A549 cells. Anticancer Res 34:5447-5452

Bernini R, Crisante F, Merendino N, Molinari R, Soldatelli MC, Velotti F (2011) Synthesis of a novel ester of hydroxytyrosol and $\alpha$-lipoic acid exhibiting an antiproliferative effect on human colon cancer HT-29 cells. Eur J Med Chem 46:439-446

Gao J, Zhao S, Halstensen TS (2016) Increased interleukin-6 expression is associated with poor prognosis and acquired cisplatin resistance in head and neck squamous cell carcinoma. Oncol Rep 35:3265-3274

Kaki SS, Grey C, Adlercreutz P (2012) Bioorganic synthesis, characterization and antioxidant activity of esters of natural phenolics and $\alpha$-lipoic acid. J Biotechnol 157:344-349

Kumar M, Singla R, Dandriyal J, Jaitak V (2017) Coumarin derivatives as anticancer agents for lung cancer therapy: a review. Anticancer Agents Med Chem https://doi.org/10.2174/ 1871520618666171229185926

Ostrowska K, Olejarz W, Wrzosek M, Głuszko A, Nowicka G, Szczepański M, Materek IB, Kozioł AE, Struga M (2017) Anticancer effects of O-aminoalkyl derivatives of alloxanthoxyletin and seselin. Biomed Pharmacother 95:1412-1424

Packer L, Witt EH, Tritschler HJ (1995) $\alpha$-Lipoic acid as a biological antioxidant. Free Radic Biol Med 19:227-50

Peng XM, Damu GL, Zhou C (2013) Current developments of coumarin compounds in medicinal chemistry. Curr Pharm Des 19:3884-930

Wang Y, Niu XL, Qu Y, Wu J, Zhu YQ, Sun WJ, Li LZ (2010) Autocrine production of interleukin-6 confers cisplatin and paclitaxel resistance in ovarian cancer cells. Cancer Lett 295:110-123

Wenzel U, Nickel A, Daniel H (2005) a-Lipoic acid induces apoptosis in human colon cancer cells by increasing mitochondrial respiration with a concomitant $\mathrm{O}_{2}-$ generation. Apoptosis 10:359-68 